\title{
DESENVOLVIMENTO DE TUBOS ERW/HFIW CASING API5CT GRAU N80 COM ALTA RESISTÊNCIA A COLAPSO*
}

\author{
Igor de Oliveira Gomes ${ }^{1}$ \\ Luis Carlos Rodrigues Melo ${ }^{2}$ \\ Luiz Paulo Boni ${ }^{3}$ \\ Marcus Wolter Ferreira ${ }^{4}$ \\ Wilson Rosa Cordeiro ${ }^{5}$
}

\section{Resumo}

O objetivo deste trabalho é desenvolver uma metodologia para aprovação de tubos com alta resistência a colapso de acordo com os requisitos da norma internacional API5CT grau N80, produzidos por tratamento térmico de tempera e revenimento, utilizando fornos de indução em tubos fabricados pelo processo de soldagem com resistência elétrica em alta frequência (ERW/HFIW). Neste trabalho são exploradas as principais propriedades mecânicas e dimensionais de um tubo de revestimento com diâmetro externo de $177,8 \mathrm{~mm}$ e parede $8,05 \mathrm{~mm}$ grau N80 processado para atingir alta resistência a colapso, onde serão apresentados os resultados do processo de qualificação para validação de sua produção em série.

Palavras-chave: API 5CT grau P110; ERW/HFIW; Produzidos por tratamento térmico; Alta resistência a colapso.

\section{TUBE DEVELOPMENT ERW/HFIW CASING API5CT GRADE N80 HIGH COLLAPSE}

\section{Abstract}

The aim of this work is supporter with a methodology for the approval of highcollapse tubes that according to the requirements of API5CT grade N80, produced by heat treatment of quenching and tempering, using induction of pipes manufactured by electrical resistance welding at high frequency (ERW / HFIW). This work see the sights of the main mechanics and dimensions properties of a casing with outside diameter of $177.8 \mathrm{~mm}$ and $8.05 \mathrm{~mm}$ wall thickness grade N80 manufactured to get high collapse, which will be showed the results of the process qualification for validation of serial production.

Keywords: API 5CT grade N80; ERW/HFIW; Produced by heat treatment; High Collapse.

1. Engenheiro Mecânico, Gerente da Qualidade, Apolo Tubulars, Lorena, São Paulo, Brasil.

2. Engenheiro Metalúrgico e de Materiais, Mestre em Engenharia Mecânica, Gerente Industrial, Apolo Tubulars, Lorena, São Paulo, Brasil.

3. Engenheiro Químico, Supervisor da Qualidade, Apolo Tubulars, Lorena, São Paulo, Brasil.

4. Engenheiro de Produção Mecânica, Supervisor da Engenharia de processos, Apolo Tubulars, Lorena, São Paulo,, Brasil.

5. Engenheiro Mecânico, Vice Presidente de Manufatura, Apolo Tubulars, Lorena, São Paulo, Brasil.. 


\section{INTRODUÇÃO}

Com a exploração de petróleo e gás dentro e fora do Brasil em águas cada vez mais profundas, devido à disponibilidade e localização das jazidas, alguns casos "Offshore", surge a necessidade de desenvolvimento de novas tecnologias em produtos como as tubulações. Segundo a Petrobras através de tecnologia e persistência, desafios que um dia pareceram impossíveis, como as águas profundas da bacia de campos nos anos 1970, foram superados, e hoje a produção do pré-sal em águas ultraprofundas já é uma realidade consolidada [1].

Em águas profundas a resistência a colapso é um fator essencial para que não haja falhas e impactos ambientais e financeiros. A norma API TR 5C3 'Technical Report on Equations and Calculations for Casing, Tubing, and Line Pipe Used as Casing or Tubing and Performance Properties Tables for Casing and Tubing" [2], define através de cálculos teóricos a pressão de colapso recomendada em relação a cada item de fabricação tendo em vista diâmetro, espessura e grau do material conforme API 5CT.

\subsection{Classificação de colapso}

Referente aos cálculos teóricos, a norma API TR 5C3 classifica o colapso em 4 tipos em relação D/t (diâmetro externo/espessura) de maneira a definir quais tubos estão sujeitos ao respectivo tipo de colapso.

1.1.1 Colapso de escoamento: não exprime a verdadeira pressão de colapso, mas sim a pressão externa que gera tensão mínima de escoamento na superfície interna do tubo - aplicável para relações $D / t \leq 13,38$. A fórmula para cálculo do colapso de escoamento "PYp" é a seguinte:

$P Y p=2 f y m n[(D / t)-1] /\left[(D / t)^{2}\right](1)$, em que:

"D" é o diâmetro externo especificado do tubo,

"fymn" é o mínimo limite de escoamento especificado,

"t" é a espessura de parede do tubo. [2]

1.1.2 Colapso plástico: resultante da deformação plástica na superfície interna do tubo - aplicável para D/t entre 13,38 e 22,47. Para seu cálculo "PP" usa-se a fórmula e os fatores mostrados abaixo:

$P P=$ fymn $[A c /(D / t)-B c]-C c(2)$, em que:

"Ac" = Constante empírica da equação histórica da API

"Bc" = Constante empírica da equação histórica da API

"Cc" = Constante empírica da equação histórica da API

"D" é o diâmetro externo especificado do tubo,

"fymn" é o mínimo limite de escoamento especificado,

"t" é a espessura de parede do tubo. [2]

1.1.3 Colapso elástico: é a mínima pressão de colapso para o range elástico aplicável a relações $D / t \geq 31,02$. A fórmula para cálculo desse tipo de colapso "PE" é a que segue:

$\mathrm{PE}=46,95 \times 10^{6} /\left[(\mathrm{D} / \mathrm{t})(\mathrm{D} / \mathrm{t}-1)^{2}\right](3)$, em que:

"D" é o diâmetro externo especificado do tubo,

"t" é a espessura de parede do tubo. [2] 
1.1.4 Colapso de transição: é a mínima pressão de colapso para o intervalo de transição entre colapso plástico e o elástico - aplicável para relações D/t $>22,47$ e $<31,02$. A fórmula para cálculo desse tipo de colapso "PT" é a que segue:

$\mathrm{PT}=$ fymn [ Fc / (D/t) - Gc ] (4), em que:

"Fc" = Constante empírica da equação histórica da API

"Gc" = Constante empírica da equação histórica da API

"D" é o diâmetro externo especificado do tubo,

"fymn" é o mínimo limite de escoamento especificado,

" $\mathrm{t}$ " é a espessura de parede do tubo. [2]

A partir das fórmulas citadas, pode-se calcular a resistência a colapso de cada item em função do diâmetro externo, espessura e grau definido pela API 5CT.

O fornecimento de materiais com maior grau API 5CT é uma possibilidade para atendimento em ambientes severos em altas profundidades; entretanto o controle do processo e das propriedades mecânicas e dimensionais dos materiais pode ser uma alternativa para aumento da resistência a colapso com menores custos de fabricação.

Alguns fabricantes oferecem como opção a linha "High Collapse" de tubos casing para poços de prospecção, que surgiu como alternativa para a utilização de tubos de grau API 5CT mais alto ou de maior espessura, porém mantendo a resistência ao colapso necessária para a aplicação e, com isso reduzindo os custos na exploração. Do ponto de vista econômico, surge a oportunidade de fornecimento de tubos com maior resistência a colapso em relação a norma API 5C3 de modo a conquistar um diferencial no mercado competitivo.

Como descrito anteriormente, o controle do processo e das propriedades mecânicas e dimensionais pode ser utilizado para aumentar a resistência a colapso. Dessa forma se faz necessário desenvolver uma metodologia para atendimento produções de tubos High Collapse atendendo aos requisitos da API 5CT; sendo necessário para este fim o conhecimento das propriedades que afetam a resistência a colapso.

\subsection{Propriedades que afetam a resistência a colapso:}

1.2.1 Relação $\mathrm{D} / \mathrm{t}$ (quociente entre o diâmetro e a espessura): é utilizada na especificação dos ranges de produtos pela API5CT, entretanto em um mesmo range há uma variação aceitável, onde a espessura e o diâmetro podem variar. Quanto menor a relação D/t, maior a resistência a Colapso. Isto pode ser evidenciado conforme cálculos teóricos de pressão de colapso a partir das 04 equações citadas anteriormente.

1.2.2 Ovalização: Kyriakides e Corona [3] mostraram que a pressão de colapso é fortemente dependente da ovalização inicial para todas as razões D/t de interesse para tubos. Verificações experimentais desse efeito foram apresentadas por Yeh e Kyriakides (1986) em que tubos com D/t entre 14 a 39, foram inicialmente ovalizados entre $0,5 \%$ e $5 \%$ em um comprimento de $12 \mathrm{D}$ e, posteriormente, colapsados. Eles verificaram que ovalizações de $1 \%$ causam reduções na pressão de colapso de 30 $40 \%$. Para ovalizações de 5\%, a redução é maior do que $50 \%$ [4].

Sobre a ovalização, com relação ao seu efeito nas fórmulas de pressão de colapso, a norma ISO 10400 afirma que, apesar de estudos teóricos indicarem que uma ovalização de $1 \%$ a $2 \%$ pode resultar em uma redução na resistência ao colapso da ordem de $25 \%$, investigações experimentais/empíricas indicam um efeito muito menor. 
Segundo Neves apud Bai et. al. [4] que estudaram a influência da ovalização inicial na pressão de colapso para tubos de parede fina e, a diferença na pressão de colapso para amplitudes de imperfeições de $0.15 \%$ e $0.5 \%$ para D/t entre 15 e 35 é de aproximadamente $15 \%$.

1.2.3 Excentricidade: Referente ao fator excentricidade - divergência dos centros do diâmetro externo e interno, Kyriakides e Corona [3] relatam que variações na espessura são mais comumente encontradas em tubos sem costura e que tais variações podem ser idealizadas como excentricidade. Desconsiderando a ovalização do tubo, Kyriakides e Corona [3] colocaram que para uma excentricidade de $5 \%$ a pressão de colapso sofre redução de $1 \%$, para uma excentricidade de $10 \%$ a redução sobe para 3,7\% e com uma excentricidade de $20 \%$ a diminuição aumenta para $11,5 \%$. Esses valores foram calculados para tubos com D/t de 20 e 35 e o resultado foi similar em ambos os casos; eles relataram que o efeito da excentricidade na pressão de colapso é relativamente menor, desde que a excentricidade seja $\leq 10 \%$.

1.2.4 Variação de espessura: A variação de espessura altera a relação D/t. Conforme enunciado anteriormente quanto menor a relação D/t, maior a resistência a colapso. Portanto variações de espessura podem reduzir a resistência a Colapso.

1.2.5 Tensão de escoamento: A tensão de escoamento é diretamente proporcional a resistência a colapso, como pode ser observado nas fórmulas teóricas para os 04 tipos de colapso.

1.2.6 Formato da curva tensão deformação: Um dos fatores mais impactante sobre o desempenho em colapso do tubo é o formato da curva Tensão-Deformação do ensaio de tração.

A figura 1 retirada do artigo de Moore [5] demonstra graficamente os limites de uma curva típica tensão deformação. Na qual o ponto "B" é caracterizado como o limite de proporcionalidade, o ponto "C" é caracterizado como limite elástico e o ponto " $D$ " é caracterizado como limite de escoamento.

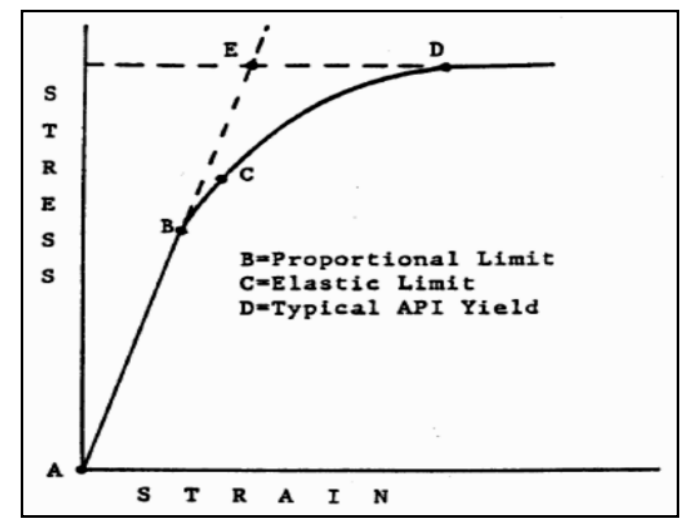

Figura 1. Limites da curva TxD segundo Moore.

A figura 2 retirada do artigo de Moore [5] demonstra um esquema de diferentes 'famílias' de curvas tensão-deformação possíveis para um mesmo material, contendo diferentes limites de proporcionalidade e elasticidade (cruzamento entre curva e a reta de $0,02 \%$ de deformação) que consequentemente resultariam em resultados de colapso diferentes. 


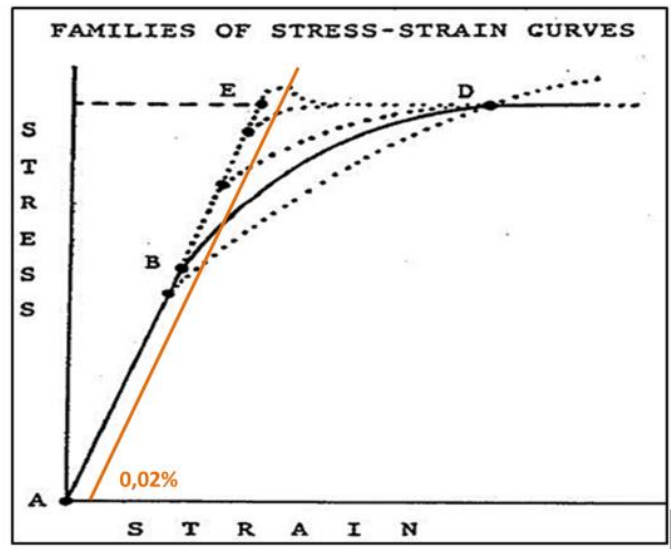

Figura 2. Diferentes Famílias de curvas TxD segundo Moore

Segundo Moore [5], cotovelos arredondados oriundos de produtos temperados e revenidos, são resultado direto de dois principais problemas de produção: 'slack quenching' (tempera não homogênea) e trabalho a frio do metal'. Isso ocorre pois ao longo da espessura do tubo, no decorrer da transformação martensítica, forma-se diferentes níveis de fibras devido o gradiente de resfriamento. Cada nível de fibra de martensíta apresenta tensão de escoamento diferente, e muitos valores baixos tornam o cotovelo da curva mais acentuado.

Para evitar o Slack quenching Moore propõe utilizar uma composição química com alta temperabilidade para facilitar a têmpera.

Para aumentar a resistência ao colapso média, é necessário estabelecer um controle do limite elástico, definindo uma tolerância de $90 \%$ do limite de escoamento (Razão entre o limite de elástico e o limite de escoamento mínimo). Conforme o artigo de Moore, o limite elasticidade é definido pela linha paralela de 0,02\% de deformação à reta da região elástica da curva de tensão deformação.

1.2.7 Desempeno a Quente: Segundo Moore [5], devido ao Efeito de Bauschinger (a mudança de direção do limite de elasticidade de um metal após uma deformação plástica) e a tensão residual introduzidos na conformação a frio durante desempeno a formato da curva tensão deformação pode ser alterado. Este efeito é dependente da temperatura de trabalho durante desempeno. Moore propõe que seja realizado desempeno à quente a cima de $370^{\circ} \mathrm{C}$.

1.2.8 Comprimento da amostra de colapso (relação L/D): Mehdizadeh [6] em seu trabalho relatou que o tamanho da amostra ensaiada também impacta diretamente sobre a pressão máxima de resistência, onde amostras de comprimento menor que sete vezes o diâmetro externo suportaram 10\% mais pressão que amostras com 8 ou 10D.

Ainda sobre o tamanho da amostra, Phillips e Moore [7] obtiveram resultados que exprimem diminuição de $10,5 \%$ na resistência ao colapso de amostras com 8D em relação a amostras ensaiadas com $2 \mathrm{D}$.

Em um estudo mais recente em tubos de $\varnothing 13$ 3/8", Pattillo [8] constatou que uma amostra com $L / D=2$ teve $83 \%$ de aumento na pressão de colapso em relação a uma amostra de $\mathrm{L} / \mathrm{D}=8$. 


\section{MATERIAIS E MÉTODOS}

2.1 Parâmetros de processos:

Após fabricação de tubos por soldagem ERW/HFIW, foi realizado tratamento térmico de austenitização e revenimento através bobinas indutoras.

Os tubos foram tratados termicamente com a temperatura de austenitização de $932^{\circ} \mathrm{C}$ e temperatura de revenimento de $655^{\circ} \mathrm{C}$ à velocidade de $7 \mathrm{~m} / \mathrm{min}$. Logo após o revenimento, todos os tubos foram submetidos ao processo de desempeno à quente em desempenadeira rotativa à $450^{\circ} \mathrm{C}$. Foram separados 03 tubos com números BP813, BP830 e BP851 para realização das análises dimensionais e ensaios.

\subsection{Medições e ensaios realizados:}

2.2.1 Medição de diâmetro, ovalização e espessura:

Os tubos foram dimensionados após o processo de tratamento térmico e desempeno a quente, onde foram avaliadas suas características dimensionais no corpo do tubo e nas pontas, conforme o perfil de ensaios da figura 5 a $50 \mathrm{~mm}$ da ponta e a cada $300 \mathrm{~mm}$ ao longo do tubo;

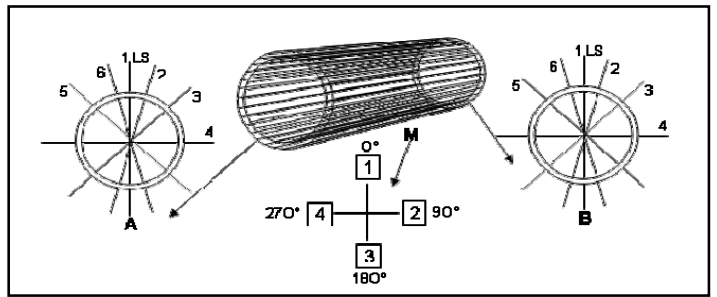

Figura 3. Perfil dos ensaios dimensionais.

\subsubsection{Ensaios de dureza HRC:}

Foi realizado ensaio de dureza nos tubos na condição temperado, e temperado e revenido em 4 quadrantes nas regiões externa, central e interna da espessura através do durômetro Rockwell RANS RS; conforme API 5CT / ISO 6508 - 1, anel $50 \mathrm{~mm}$.

\subsubsection{Ensaio de achatamento:}

O ensaio de achatamento foi realizado com duas amostras para cada tubo, uma a $0^{\circ}$ e outro a $90^{\circ}$ em relação à linha de solda

\subsubsection{Ensaio de impacto Charpy-V:}

Os ensaios de charpy foram realizados em amostras retiradas no sentido transversal ao eixo do tubo, posicionado o entalhe em duas regiões, na linha de solda e no metal de base em 5 temperaturas diferentes conforme as especificações da norma ISO 148-1. Os corpos de prova foram usinados no tamanho reduzido de $10 \times 7,5 \times$ $55 \mathrm{~mm}$ e seus resultados foram corrigidos através de aplicação de um fator de correção de 0,75 para o tamanho full size.

\subsubsection{Ensaio de tração longitudinal:}

Foi realizado ensaio de tração no equipamento Kratos com capacidade de 100 ton em corpos de prova conforme ASTM A370, em 04 quadrantes retirados na posição 
longitudinal dos tubos.Foram analisadas as curvas de tensão deformação convencional de engenharia e a curva de tensão deformação real

\subsubsection{Ensaio de pressurização externa (colapso)}

As amostras para o ensaio de colapso foram cortadas com comprimento de 11D (1956mm). Os ensaios de para avaliação da resistência ao colapso (pressão de colapso) foram realizados no LTS (Laboratório de Tecnologia Submarina) da COPPE/UFRJ. Todos os ensaios seguiram o mesmo procedimento em que as amostras foram ensaiadas sem água e ventilados em seu interior para a atmosfera através de um tubo (figura 4c). Após a preparação, colocação da amostra e água na câmara, o ensaio se inicia com a pressurização da câmara com água, feita diretamente pela unidade de pressurização situada ao lado do computador (figura 4d) que fornece, monitora e controla a pressurização durante todo o ensaio. A taxa de incremento da pressão é controlada durante todo o ensaio para que seja mantida a linearidade do aumento de pressão (gráfico do ensaio figura 4b) a uma taxa de 50 Psi por minuto até que ocorra o colapso.

\subsubsection{Equipamento utilizado para o ensaio de colapso:}

- Câmara hiperbárica horizontal, com capacidade para 7500 psi e comprimento de 5 metros (figura 4a),

- Malha para medição de pressão KMPP-003 composta por um transdutor de pressão marca Ashcroft para 10000 psi,

- Unidade de pressurização hidro-pneumática marca Flutrol/Haskel com capacidade para 20Kpsi (figura 4d),

- Computador com software de aquisição de dados e controle de processo "Lab

View" (figura 4b),

- Cabeças de vedação, para a selagem das extremidades do tubo (figura 4c),

- Massa subaquática, similar à resina Epóxi para vedação interna da amostra,

- Resina vulcanizável à frio para selagem externa da amostra (figura 4c),

- Torquímetro manual de estalo para aplicação do torque correto nos parafusos durante o fechamento da tampa da câmara não danificando a gaxeta de vedação.

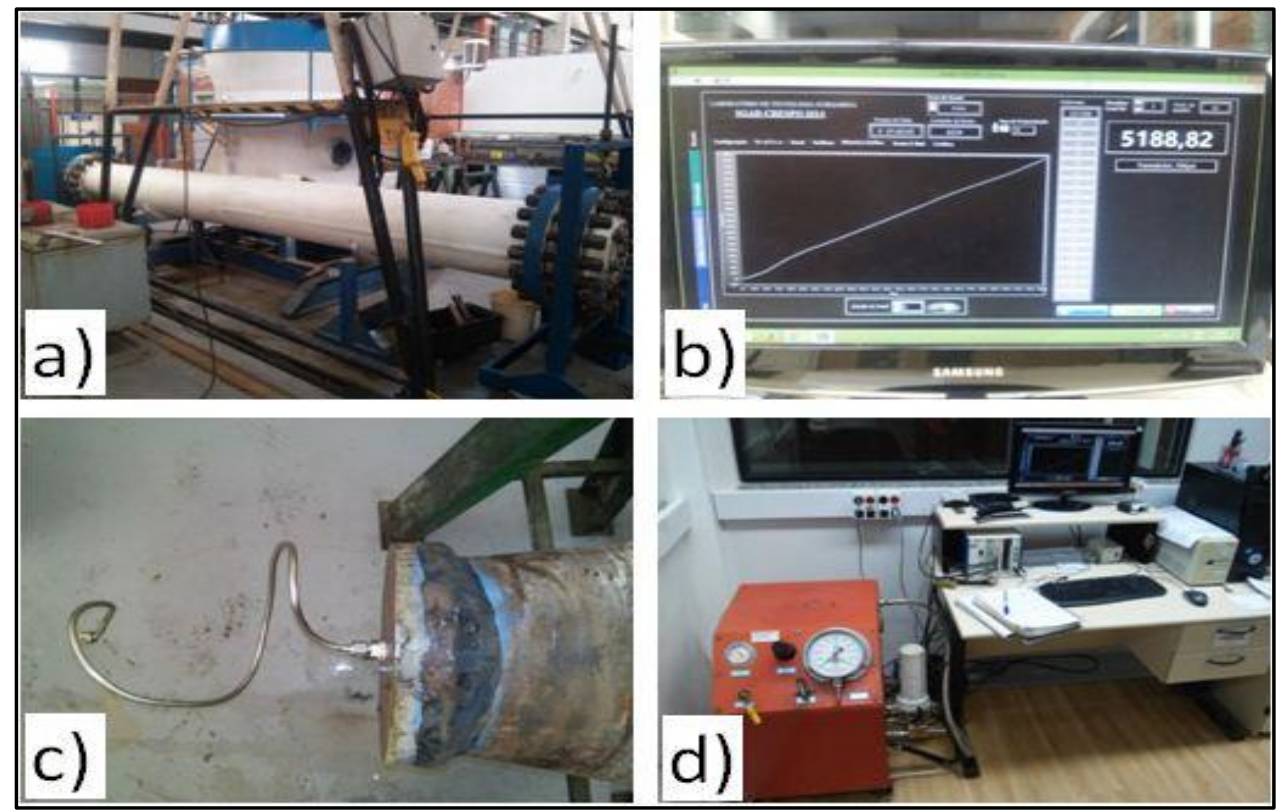

Figura 4. Equipamentos e amostra para ensaio de colapso (LTS - COPPE/UFRJ). 


\section{RESULTADOS E DISCUSSÃO}

A composição química do aço utilizado pode ser visualizada na tabela 1.

Tabela 1. Composição Química do aço utilizado

\begin{tabular}{cccccccccc}
\hline $\begin{array}{c}\text { Especificação } \\
\text { [\%] }\end{array}$ & C & Mn & Mo & Cr & Ni & Cu & $\begin{array}{c}\mathbf{P} \\
\text { Máx }\end{array}$ & $\begin{array}{c}\text { Máx } \\
\text { Máx }\end{array}$ & Si \\
\hline API5CT N80 & - & - & - & - & - & - & 0,030 & 0,030 & - \\
\hline Apolo N80 & 0,249 & 1,432 & 0,006 & 0,018 & 0,013 & 0,036 & 0,016 & 0,005 & 0,234 \\
\hline
\end{tabular}

Os únicos requisitos de composição química para o grau N80 conforme API5CT são as quantidades máximas de enxofre e fósforo, sendo em ambos 0,030\% no máximo. Pode-se observar que o aço utilizado atende a estes requisitos.

Segundo a API5CT a resistência a colapso para tubos de diâmetro externo 7", espessura de $8,05 \mathrm{~mm}$, grau N80 é 3830 PSI.

Os resultados de pressão de colapso estão dispostos na tabela 2.

Tabela 2. Resultados do ensaio de achatamento

\begin{tabular}{lcccc}
\hline Amostra & $\begin{array}{c}\text { Resistência a } \\
\text { Colapso [PSI] }\end{array}$ & $\begin{array}{c}\text { Incremento da Pressão } \\
\text { de Colapso em relação } \\
\text { a API 5CT [\%] }\end{array}$ & $\begin{array}{c}\text { API 5CT Pressão } \\
\text { de Colapso N80 } \\
\text { [PSI] }\end{array}$ & $\begin{array}{c}\text { Comprimento } \\
\text { das Amostras } \\
\text { ensaiadas }\end{array}$ \\
\hline BP813 & 6373 & $66 \%$ & & \multirow{2}{*}{3830} \\
\cline { 1 - 2 } BP830 & 6627 & $73 \%$ & & $11 \mathrm{D}$ \\
\hline BP851 & 6670 & $74 \%$ & & \\
\hline
\end{tabular}

As amostras foram cortadas e ensaiadas com 11D (11 vezes o diâmetro externo nominal do tubo) o que torna o ensaio mais severo, conforme mencionado, quanto maior o comprimento da amostra menor a resistência a colapso. A API5C3 solicita ensaios com comprimento mínimo de 8D. É possível notar que todas as amostras tiveram resultado $66 \%$ maior do que a pressão teórica de colapso descrita pela API5C3.

As figuras 5 e 6 mostram os resultados de energia absorvida no ensaio de charpy em amostras de metal base e linha de solda respectivamente.

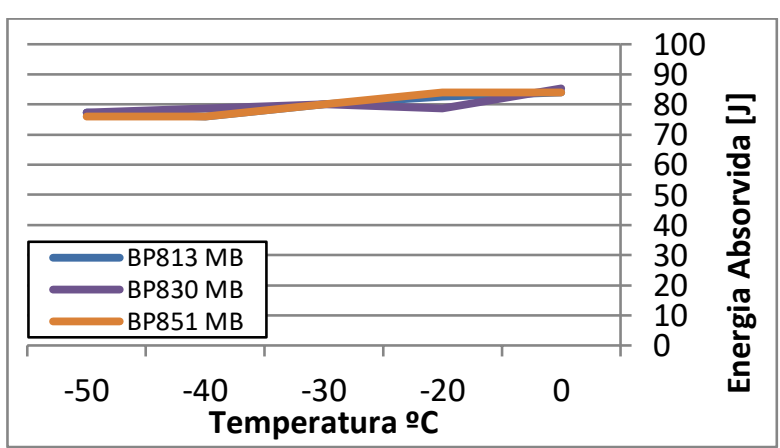

Figura 5. Charpy transversal - Metal Base

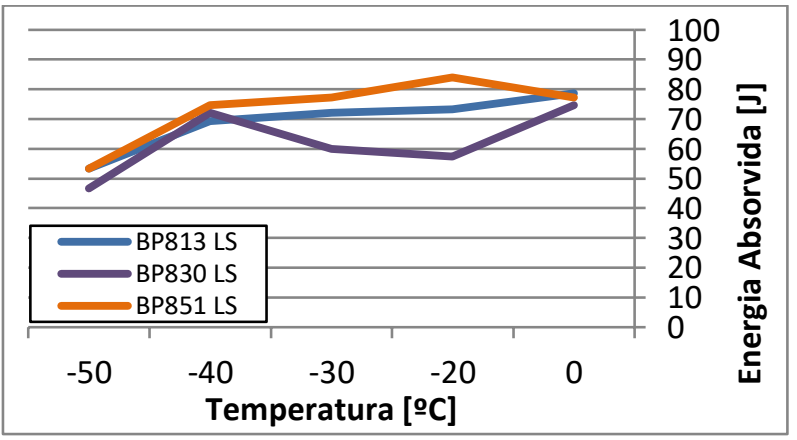

Figura 6. Charpy transversal - linha de solda

Todos os resultados obtidos atendem a especificação API para o grau N80 diâmetro 7 " e espessura 9,05mm: energia absorvida mínima de $11 \mathrm{~J}$ à temperatura de $0^{\circ} \mathrm{C}$. 
Os resultados do ensaio de achatamento estão dispostos na tabela 3.

Tabela 3. Resultados do ensaio de achatamento

\begin{tabular}{cccc}
\hline Amostra & $\begin{array}{c}\text { Achatamento 0 } \\
{[\mathrm{mm}]}\end{array}$ & $\begin{array}{c}\text { Achatamento 90 } \\
{[\mathrm{mm}]}\end{array}$ & $\begin{array}{c}\text { API 5CT Grau } \\
\text { N80 (Máx) [mm] }\end{array}$ \\
\cline { 1 - 3 } BP813 & 0 & 70 & \\
\cline { 1 - 3 } BP830 & 0 & 81 & 115 \\
\cline { 1 - 3 } BP851 & 0 & 80 & \\
\hline
\end{tabular}

Todas as amostras foram aprovadas e foi possível verificar que o tubo que teve menor resistência a colapso (BP813) foi o que apresentou melhor resultado no achatamento a $90^{\circ} \mathrm{em}$ relação à linha de solda. As 3 amostras ensaiadas a $0^{\circ}$ tiveram resultados iguais.

Os resultados da inspeção dimensional estão dispostos na tabela 4.

Tabela 4. Dimensional dos tubos

\begin{tabular}{lcccc}
\hline \multicolumn{1}{c}{ Dimensão } & BP813 & BP830 & BP851 & API 5CT Grau N80 \\
\hline Diâmetro Mínimo [mm] & 179,1 & 179,2 & 179,1 & 176,9 \\
\hline Diâmetro Máximo [mm] & 179,9 & 179,7 & 180,0 & 179,6 \\
\hline Diâmetro Médio [mm] & 179,5 & 179,4 & 179,5 & 178,3 \\
\hline Ovalização [\%] & $0,45 \%$ & $0,28 \%$ & $0,5 \%$ & - \\
\hline Espessura Mínima [mm] & 7,94 & 7,88 & 7,86 & 7,80 \\
\hline Espessura Máxima [mm] & 8,32 & 8,31 & 8,27 & 8,51 \\
\hline Espessura Média [mm] & 8,21 & 8,20 & 8,17 & 8,15 \\
\hline Variação da espessura [mm] & 0,27 & 0,32 & 0,31 & - \\
\hline
\end{tabular}

A relação D/t (Diâmetro/espessura), ficou em 21,8. Conforme mencionado, quanto menor a relação $D / t$ maior a resistência a colapso.

Pode se observar que o diâmetro externo médio dos tubos está entre 179,4 e 179,5mm; valor próximo ao diâmetro máximo da API5CT. Este diâmetro alto aumenta a relação $\mathrm{D} / \mathrm{t}$, que reduz a resistência a colapso.

Pode-se observar que os tubos tiveram resultados de espessura média próxima a espessura média da API5CT e que houve pouca variação de espessura entre os tubos. A ovalização, ficou entre $0,28 \%$ e $0,5 \%$. Conforme mencionado por Neves, para relação de D/t entre 15 e 35, ovalizações entre $0,15 \%$ e 0,5\% reduzem em $15 \%$ a resistência a colapso. Pode-se afirmar que a variação de ovalização encontrada nos tubos não foi o fator preponderante para o resultado de colapso, uma vez que o tubo BP851, com maior ovalização de $0,5 \%$ obteve melhor resultado de colapso: 6670PSI.

A média dos resultados de dureza na condição temperado e na condição temperado e revenido podem ser observados na tabela 5 :

Tabela 5. Resultado médio de dureza dos tubos

\begin{tabular}{lccccc}
\hline Numero do Tubo & $\begin{array}{c}\text { Dureza } \\
\text { Mínima }\end{array}$ & $\begin{array}{c}\text { Dureza } \\
\text { média }\end{array}$ & $\begin{array}{c}\text { Dureza } \\
\text { Máxima }\end{array}$ & $\begin{array}{c}\text { Dureza Mínima } \\
\text { API5CT (50\% } \\
\text { martensita) }\end{array}$ & $\begin{array}{c}\text { Dureza (90\% } \\
\text { Martensita) }\end{array}$ \\
\hline Temperado & 40 & 42,1 & 44 & 35,6 & 41,5 \\
\hline Temperado e Revenido & 20 & 23,5 & 28 & - & - \\
\hline
\end{tabular}


A partir dos resultados de dureza dos tubos temperados, pode-se observar que a média de dureza atingiu $90 \%$ de martensita, o que pode explicar o alto resultado de resistência a colapso.

A norma API5CT não estabelece dureza máxima e mínima para tubos temperados e revenidos no grau $\mathrm{N} 80$ e a dureza encontrada ficou dentro do esperado com variações pontuais de dureza máxima.

Os resultados de tração da curva convencional de engenharia estão dispostos conforme tabela 6.

Tabela 6. Resultados do ensaio de tração (Tensão - Deformação) - Curva Engenharia

\begin{tabular}{|c|c|c|c|c|c|c|c|}
\hline \multirow[t]{2}{*}{$\begin{array}{l}\text { Numero } \\
\text { do Tubo }\end{array}$} & \multirow[t]{2}{*}{$\begin{array}{c}\text { Limite de } \\
\text { escoamento } \\
\text { [MPa] }\end{array}$} & \multirow[t]{2}{*}{$\begin{array}{c}\text { Limite de } \\
\text { Resistência } \\
\text { [MPa] }\end{array}$} & \multirow[t]{2}{*}{$\begin{array}{c}\text { Alongamento } \\
{[\%]}\end{array}$} & \multicolumn{2}{|c|}{$\begin{array}{c}\text { Limite de } \\
\text { escoamento API } \\
\text { 5CT Grau N80 } \\
\text { [MPa] }\end{array}$} & \multirow{2}{*}{$\begin{array}{c}\text { Limite de } \\
\text { resistência } \\
\text { API 5CT Grau } \\
\text { N80 [MPa] } \\
\text { Mín }\end{array}$} & \multirow[t]{2}{*}{$\begin{array}{c}\text { Alongamento } \\
{[\%]}\end{array}$} \\
\hline & & & & Mín & Máx & & \\
\hline BP813 & 699 & 793 & 27,8 & \multirow{3}{*}{552} & \multirow{3}{*}{758} & \multirow{3}{*}{689} & \multirow{3}{*}{16} \\
\hline BP830 & 726 & 815 & 28,0 & & & & \\
\hline BP851 & 722 & 814 & 30,3 & & & & \\
\hline
\end{tabular}

Os 03 tubos ensaiados atenderam às propriedades mecânicas especificadas pela API5CT para o Grau N80 para tubo com diâmetro 7" espessura de 8,05mm. Pode-se obsevar que o limite de escoamento dos 03 tubos ficou entre 699Mpa e 722Mpa; próximo ao limite máximo especificado pela norma: 758Mpa. Este resultado pode explicar a alta resistência a colapso, $66 \%$ maior do que o especificado pela API5C3. Também podemos observar que o tubo BP813 com menor limite de escoamento foi o que apresentou menor resistência a colapso: 6373Psi.

As figuras 7, 8 e 9 mostram as curvas reais de tensão deformação - Ln $(1+\varepsilon)$

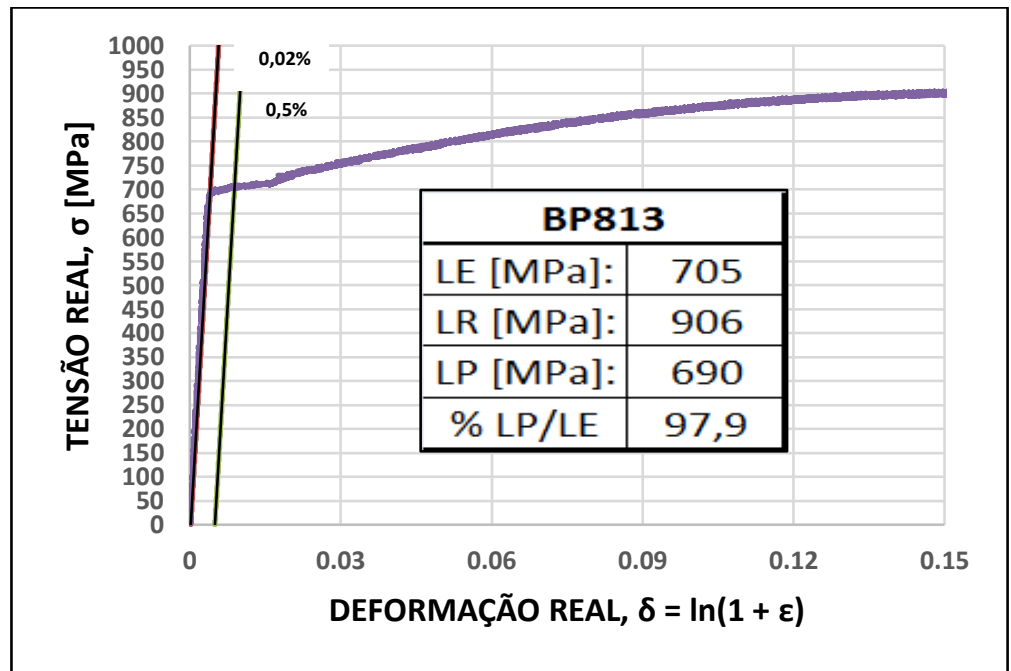

Figura 7. Curva de tração real - BP813 


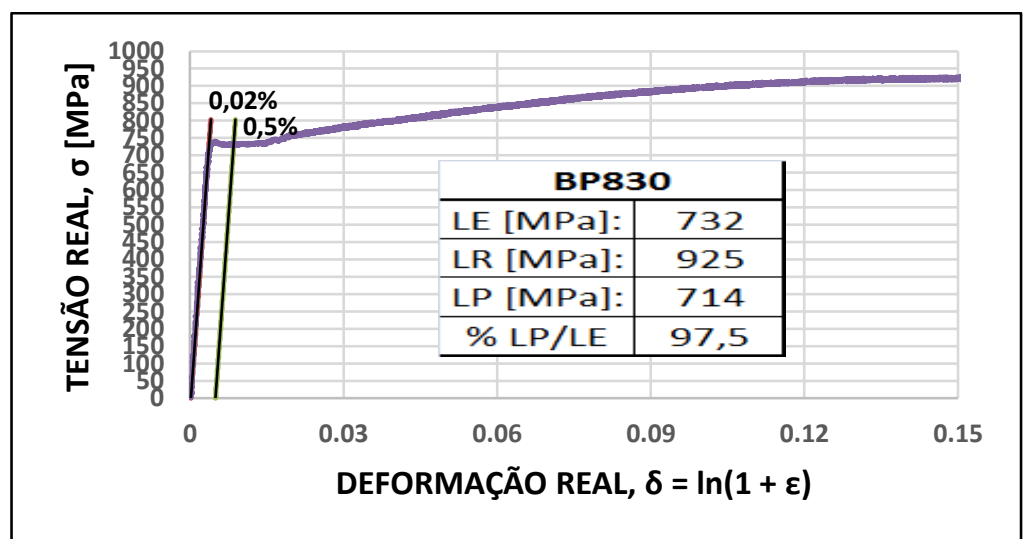

Figura 8. Curva de tração real - BP830

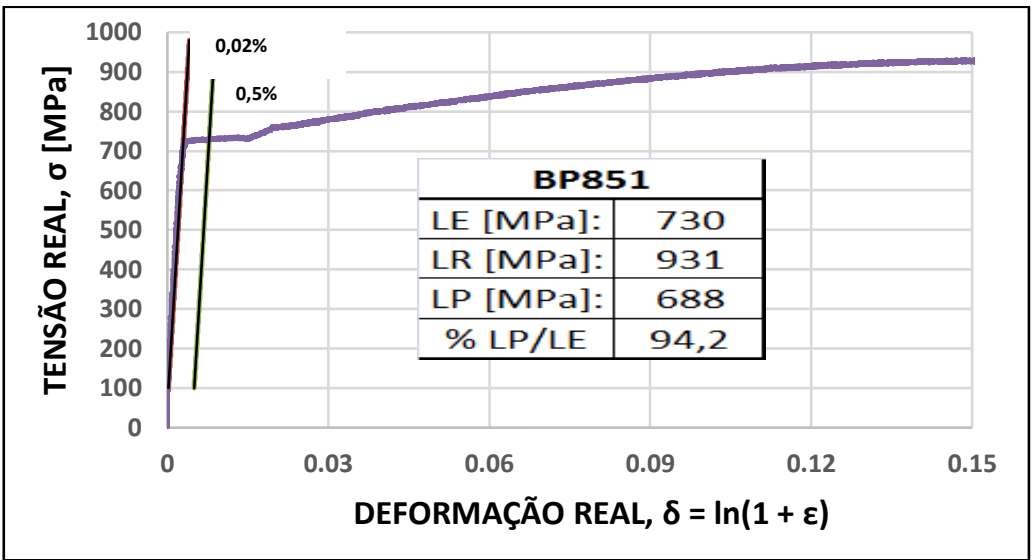

Figura 9. Curva de tração real - BP851

A partir das curvas reais apresentadas é possível observar que as curvas dos tubos tratados termicamente apresentam formato com "cotovelos não arredondados", conforme mencionado por Moore, característica apresentada em aços com homogeneidade microestrutural que aumentam a resistência a colapso; esta propriedade condiz com a dureza encontrada nos tubos temperados e com o alto resultado de colapso apresentado.

A partir da tabela 7, podemos observar os resultados de propriedades mecânicas do ensaio de tração para curva real dos 03 tubos estudados.

Tabela 7. Resultados do ensaio de tração (Tensão - Deformação) - Curva Real

\begin{tabular}{lcccc}
\hline $\begin{array}{c}\text { Numero } \\
\text { do Tubo }\end{array}$ & $\begin{array}{c}\text { Limite de } \\
\text { escoamento } \\
\text { [MPa] }\end{array}$ & $\begin{array}{c}\text { Limite de } \\
\text { Plasticidade } \\
\text { [MPa] }\end{array}$ & $\begin{array}{c}\text { Razão entre o Limite } \\
\text { de Plasticidade e o } \\
\text { Limite de escoamento } \\
\text { médio (API 5CT) }\end{array}$ & $\begin{array}{c}\text { Limite de } \\
\text { Resistência } \\
\text { [MPa] }\end{array}$ \\
\hline BP813 & 705 & 690 & $97,9 \%$ & 906 \\
\hline BP830 & 732 & 714 & $97,5 \%$ & 925 \\
\hline BP851 & 730 & 688 & $94,2 \%$ & 931 \\
\hline
\end{tabular}

Conforme descrito anteriormente, quanto maior o limite de plasticidade, maior a resistência a colapso. $\mathrm{O}$ alto resultado da razão entre o limite de plasticidade e 0 limite de escoamento, acima de $94,2 \%$ pode explicar o alto resultado de resistência a colapso dos 03 tubos estudados. Conforme mencionado, Moore recomenda um valor de $90 \%$ para a razão ente o limite de plasticidade e o limite de escoamento, para obtenção de altos resultados de resistência a colapso. 


\section{CONCLUSÃO}

A análise de composição química comprova que o material atende as especificações da norma API5CT.

O ensaio de charpy demonstrou que a energia absorvida apresentou valores elevados em relação ao requisito normativo, apresentando um comportamento dúctil mesmo para temperaturas abaixo da especificada.

O ensaio de achatamento mostrou que o metal base e a solda, do material apresentam alta resistência e deformação dúctil atendendo aos requisitos da API5CT.

A análise dimensional mostra que os resultados apresentaram pequenas variações pontuais com valores médios conforme as especificações da norma API5CT.

Através dos resultados de dureza foi possível identificar que a quantidade de martensita transformada no processo de tempera foi superior ao mínimo de $50 \%$ exigido por norma, obtendo aproximadamente em $90 \%$ e garantido dessa forma uma maior homogeneidade microestrutural.

No ensaio de tração foi verificado que todos os resultados atendem os requisitos do grau N80. O limite de escoamento manteve-se em uma faixa restrita próxima ao limite superior de 758MPa especificado pela norma de fabricação.

$\mathrm{Na}$ análise das curvas reais é possível notar que as mesmas apresentam "cotovelos não arredondados" conforme mencionado por Moore, característica de materiais com homogeneidade microestrutural. Pode-se obsevar que o limite de plasticidade foi superior a $94 \%$ do limite de escoamento do material, acima dos $90 \%$ recomendados por Moore para obtenção de altas resistências à colapso.

Os resultados de resistência a colapso dos 03 tubos com diâmetro externo 7", espessura de $8,05 \mathrm{~mm}$ e grau N80, foram pelo menos $66 \%$ maior do que a resistência a colapso teórica atribuída pela API5C3 de 3830Psi, o que mostra que as propriedades do material fabricado podem ser qualificadas com requisitos extras de equipamentos para utilização em ambientes severos de águas profundas.

\section{REFERÊNCIAS}

1 Petróleo Brasileiro S.A [página da internet]. Rio de Janeiro: Petrobras [acesso em 31/05/2017]. Disponível em: http://www.petrobras.com.br/pt/nossas-atividades/areas-deatuacao/ exploracao-e-producao-de-petroleo-e-gas/

2 API TR 5C3. Technical Report on Equations and Calculations for Casing, Tubing, and Line Pipe Used as Casing or Tubing and Performance Properties Tables for Casing and Tubing, 2008.

3 KYRIAKIDES, S., CORONA, E. Mechanics of Offshore Pipelines Vol.1 - Buckling and Collapse. $1^{\mathrm{a}}$ ed. 2007. $448 \mathrm{p}$.

4 NEVES, H. G., Colapso de tubos de revestimento submetidos à tração axial e pressão externa. Dissertação de Mestrado. Universidade Federal do Rio de Janeiro, Brasil, 2014.

5 MOORE, P, W. Manufacturing Techniques in Producing Consistent High Collapse Properties. Apresentação para a sexagésima terceira conferência de padronização da API, New Orleans, Louisiana 1986.

6 MEHDIZADEH, P. Casing Collapse Performance. Continental Oil Company, Oklahoma 1974.

7 MOORE, P, W., PHILLIPS, J. Influence of Collapse Test Length on Collapse Data, 1987.

8 PATTILO, P, D. Effect of Length : Diameter Ratio on Collapse Test Results and Frame Design. SPE/IADC Drilling Conference, Amsterdam, 2007. 